\title{
Understanding the Prevalence and Situational Characteristics of Hostage and Crisis Negotiation in England: an Analysis of Pilot Data from the National Negotiator Deployment Database
}

\author{
Amy Rose Grubb ${ }^{1,2}$ (D) \\ Published online: 18 February 2020 \\ (C) The Author(s) 2020
}

\begin{abstract}
The following paper outlines the findings from an exploratory analysis of the hostage and crisis negotiator deployment database that was piloted within Norfolk and Suffolk Constabularies prior to national rollout of a centralised and standardised online recording mechanism for negotiator deployments across the majority of police forces within the UK. The research utilised a descriptive research design, whereby the secondary data from an initial 24-month recording period was analysed using descriptive statistics. The findings provide a descriptive representation of (1) the socio-demographic characteristics of the subjects encountered by negotiators, (2) the typical situational characteristics/circumstances in which subjects present and the most frequently encountered subject impact factors and (3) how hostage/crisis incidents are typically resolved. The findings are discussed with relevance to the implications for negotiator practice and policy. An emphasis is placed on identification of recommendations for improving the discipline of hostage and crisis negotiation via the standardisation of deployment recording and targeted/focused training and continuing professional development of negotiators based on the characteristics of deployments observed.
\end{abstract}

Keywords Hostage negotiation $\cdot$ Crisis negotiation $\cdot$ Police negotiation $\cdot$ Police database

\section{Introduction}

Hostage and crisis negotiation $(\mathrm{HCNn})^{1}$ is an important aspect of modern-day policing, with hostage and crisis negotiators (HCNs) serving a vital role in the resolution of hostage and crisis incidents. HCNs can be utilised/are deployed in a variety of different scenarios ranging from responding to suicidal individuals to dealing with kidnap and extortion cases (Grubb

\footnotetext{
${ }^{1}$ The following abbreviations are used throughout this paper: HCN: hostage and crisis negotiator; HCNs: hostage and crisis negotiators; HCNn: hostage and crisis negotiation; and HNC: hostage negotiator coordinator. In addition to this, the term "subject" is utilised to refer to either a "hostage-taker" or "individual-in-crisis", depending on the context of the hostage or crisis situation being referred to.
}

Amy Rose Grubb

a.grubb@worc.ac.uk

1 School of Psychological, Social and Behavioural Sciences, Coventry University, Priory Street, Coventry CV1 5FB, UK

2 Present address: School of Psychology, University of Worcester, Henwick Grove, Worcester WR2 6AJ, UK et al. 2019). Research conducted in the United States of America (USA) has helped to build a picture of HCN deployment, identifying several broad categories (Boltz et al. 1992; McMains and Mullins 1996), with the caveat that the subtypes are not entirely mutually exclusive (Miller 2005). According to McMains and Mullins (2014), categories include the following: (1) barricaded subject incidents, (2) high-risk suicide attempts, (3) domestic incidents, (4) prison and jail riots, (5) mental health warrants, (6) high-risk warrants, (7) debriefing in crisis incidents, (8) stalking incidents, (9) violence in the workplace and (10) school violence. Research of this ilk, conducted in the USA, has benefitted from the existence of the Hostage Barricade Database System (HOBAS) ${ }^{2}$ which contains information relating to national $\mathrm{HCN}$ deployments across the USA. The HOBAS database has, therefore, enabled

\footnotetext{
2 "HOBAS is a centralised repository for hostage and barricade incident data and resolution outcomes. The system provides data collection functions search capabilities, and statistical analysis. The Hostage Barricade Database System consists of sixty fields documenting hostage and barricade situations. The fields include information on each incident, nature of contact with subject, information about the subject and victim, resolution of the incident (surrender, escape, sniper shot, suicide etc.), and a narrative report on the incident" (Department of Justice 2006).
} 
empirically verified categories of HCN deployment to be identified in the USA and has facilitated the nuanced understanding of hostage and crisis incidents from a situational and characteristic perspective.

Research conducted by Mohandie and Meloy (2010) with HOBAS data, for example, provided a detailed picture of hostage, barricade and jumper incidents from 1998 and 2006 ( $N=84$ cases) and included information relating to the following: (1) incident characteristics (i.e. type of shooting, fatalities, use of alternatives to deadly force, setting and location of incident, type of crime), (2) subject data (i.e. demographics and subject behavioural information, weapon possession, weapon status, violence against others during the incident, threats) and (3) outcomes (i.e. whether injury or death occurred to anyone involved in the incident). Initial analysis revealed that $45(53.6 \%)$ of the cases were classified as "barricade incidents", $38(45.2 \%)$ were classified as "hostage incidents" and one was classified as a "jumper incident" (1.2\%) providing insight into the type of incidents being responded to by federal/police HCNs in the USA. HOBAS has, however, come under much criticism, particularly in relation to the reliability/validity of its data (Alexander 2011), and is unlikely to provide a full and exhaustive picture of HCNn in the USA. This is because HCNs self-select whether to be involved with HOBAS, both in terms of whether data regarding deployments are submitted in the first place, and which deployments are submitted, thereby presenting a biased and nonrepresentative picture of HCN deployment (see Lipetsker 2004 for a full discussion). Despite these criticisms, for many years, HOBAS represented one of the only national $\mathrm{HCN}$ databases that could be used to quantitatively and empirically understand HCN deployment.

Police forces in the United Kingdom (UK) equally recognise the varied nature of $\mathrm{HCN}$ deployment and acknowledge the contribution that can be made by HCNs to a variety of different operational scenarios. This is demonstrated by the "Use of Negotiators by Incident Commanders Briefing Paper", which states that HCNs are beneficial within the following incidents: suicide intervention, missing persons, political protest, people in crisis, supporting incident commanders in firearms operations, offences of kidnap and/or extortion, criminal sieges and terrorist hostage incidents (ACPO and NPIA 2011). Similar messages are demonstrated at regional level, e.g. the West Mercia Police Hostage and Crisis Negotiator Policy states that: "The role of Hostage and Crisis Negotiator is recognised across the country as an invaluable option in the safe resolution of incidents ranging from domestic and criminal sieges, to suicide intervention, kidnap and extortion, product contamination and terrorism" (West Mercia Police 2009, p. 2). Grubb et al.'s (2019) work equally reinforces the varied nature of $\mathrm{HCN}$ deployment, identifying 12 characteristically and situationally different deployment categories based on qualitative interviews conducted with HCNs from nine English police forces. However, despite this recognition from an operational (and self-reported) perspective, there is no published research that empirically identifies the situational characteristics of $\mathrm{HCN}$ deployment using actual police deployment reports. Furthermore, historically, there has been no centralised database to record HCN deployments across the entire of the $\mathrm{UK}$ in a consistent manner, which has made it difficult to conduct empirical research within this realm, particularly when wanting to compare data across geographical regions/forces. A similar database has existed in Scotland since 2005 and Alexander's (2011) research using this database, for example, provides some insight into the characteristics of Scottish HCN deployments within a 3-year period (2005-2008), thereby furthering understanding of HCN on a national level and providing opportunities to enhance evidence-based policing within Scotland.

The HCN role is both diverse and constantly evolving, in line with the advancement of technology and modern society. Anecdotally, one might also propose that the need for HCNs is likely to increase, in line with increasing numbers of people experiencing mental health problems. For example, data taken from the 2007 Adult Psychiatric Morbidity Survey identified that $15.5 \%$ of $16-64$ year olds in England met the criteria for one common mental disorder in 1993, whereas this figure had risen to $17.6 \%$ in 2007 (McManus et al. 2009). A similar and more abrupt trend has been observed since 2007, with the 2014 health survey for England concluding that $26.0 \%$ of adults reported having ever been diagnosed with at least one mental health problem (Bridges 2015). Based on this current trajectory, it has been predicted that by 2030 "there will be approximately two million more adults in the UK with mental health problems than there were in 2013" (Mental Health Foundation 2013, p.2). The findings are slightly more complicated when considering suicide rates; however, a sharp and analogous trend is revealed for men aged 45-54 and men aged 55-64 where an increase of $37.0 \%$ and $29.0 \%$ has been observed, respectively, since 2006 (University of Manchester 2015). Such findings are particularly relevant, when considering evidence suggesting that male subjects are more likely to be encountered by HCNs and the fact that suicide/self-harm intervention forms a key part of the HCN role. Alexander's (2011) findings, for example, revealed that $83.0 \%$ of subjects encountered by Scottish HCNs over a 3-year period were male, and $59.0 \%$ of incidents involved a threat to the perpetrator's life through the risk of deliberate self-harm. These findings not only highlight the importance of emergency services being equipped to deal with mental health problems but equally also suggest that the $\mathrm{HCN}$ role is more relevant and salient than ever. However, without access to UK HCN deployment data on a national level, it is impossible to identify whether the trends observed in Scotland generalise to England, Wales and Northern Ireland or to empirically 
validate the prevalence of mental health-related $\mathrm{HCN}$ deployments, for example.

Understanding the nature and extent of $\mathrm{HCN}$ deployment from a national, culturally specific perspective is important for several reasons. Firstly, identification of an accurate picture of $\mathrm{HCN}$ deployment is important for HCN training and continuing professional development (CPD) and secondly has operational relevance by providing opportunities to perform preventative operational policing tasks such as target hardening, i.e. understanding incident situational characteristics and geographical "hot spots" allows extra resources to be put in place to prevent incidents from occurring in the future. A simple representation of the latter would be identification of a suicide "hot spot" as a multi-storey car park within a city centre. Once identified, work could be carried out in collaboration with local authorities/car park owners to reduce risk in this location (i.e. by enhancing security, surveillance and architectural measures preventing subjects from being able to access the roof/ledges). Reduction of opportunity in a logistical sense could be enough to prevent someone with suicidal ideation from attempting to commit suicide, thereby highlighting the opportunities for utilising $\mathrm{HCN}$ deployment data in a proactive and preventative policing manner.

Mapping the most frequently occurring incidents and their situational characteristics can also be used to enhance $\mathrm{HCN}$ efficacy and performance and inform training and CPD in an evidence-based manner. If data reveals, for example, that $\mathrm{HCN}$ "bread and butter" in the UK involves dealing with suicidal individuals who may be experiencing mental health problems and/or are under the influence of drugs and/or alcohol, resources could be directed towards understanding suicidal behaviour and effective suicide intervention techniques. This could extrapolate, for example, to enhancing provision of material within training/CPD courses to focus more specifically on mental health problems, specific patterns of behaviour and effectively responding to suicidal individuals or to the increased utilisation of mental health advisors to support HCN deployment. Historically, these types of recommendation, based on deployment data, have not been possible in England, Wales and Northern Ireland, due to the lack of a centralised database. Reassuringly, however, work has been carried out to develop a standardised electronic web-based system that can record HCN deployment data on a national level (across the entire of the UK). The national negotiator deployment database (NNDD) was initially set up in 2015 with a pilot project involving two forces (Norfolk and Suffolk Constabularies), and the database was rolled out nationally to the majority of police forces in England, Wales and Northern Ireland in January 2018. It is anticipated that this database will provide opportunities to understand HCN deployment on a national/international level, will bridge the gap between research and practice in policing and can be used to create a professional discipline of evidencebased $\mathrm{HCN}$ in the UK.
The aim of the current research, therefore, was to analyse the first set of HCN deployment data obtained from two English police forces over a 24-month period (as a pilot study for the national rollout of the database), with the intention of providing an exploratory and descriptive analysis of the deployments completed by HCNs in the Norfolk and Suffolk regions. The project also addresses the following research questions:

RQ1. "Who?": What is the socio-demographic and behavioural profile of subjects (i.e. hostage takers/individuals-in-crisis) involved in HCNn?

RQ2. "What and where?": What is the contextual profile of hostage and crisis incidents? I.e. what are the key situational/behavioural characteristics of $\mathrm{HCN}$ deployments?

RQ3. "How?": How are hostage/crisis incidents resolved by HCNs?

\section{Method}

\section{The Database}

The database utilised within this study consisted of the pilot version of the national negotiator deployment database (NNDD) that was originally trialled within two English forces (i.e. Norfolk and Suffolk Constabularies). Permission was granted by Norfolk Constabulary for the principle investigator to have access to the data in the form of two Microsoft excel spreadsheets in order for the project to be completed. The data covers HCN deployments between the period of January 2015 and December $2016^{3}$ and includes data relating to a total of 166 deployments. The raw data originated from the Hostage and Crisis Negotiator Incident Return and Debrief Form which is completed by HCNs after a deployment via a secure online system which records information relating to the following: (1) incident information; (2) negotiators engaged; (3) roles performed; (4) incident type, tactics and communication; (5) impact factors; (6) negotiator use; (7) assessment of method of communication used; (8) use of third-party intermediaries and advisors; (9) behavioural change stairway model; (10) techniques of influence and persuasion; and (11) outcome and evaluation.

\section{Data Security}

In light of the sensitive nature of the data, the principle investigator was required to maintain high levels of security and

\footnotetext{
${ }^{3}$ Norfolk Constabulary data covers the period from January 2015 to December 2016 and Suffolk Constabulary data covers the period from March 2015 to December 2016.
} 
confidentiality throughout the duration of the project. This translated to removal of all personally identifying information from the deployment records before provision of the Microsoft excel spreadsheets to the principle investigator and storage of the dataset in password protected files on a password protected computer/USB stick. All data has been analysed in an anonymous aggregated format and, as such, individual subject's identities have been protected. All recording and storage of data was conducted in line with the Data Protection Act (1998) and General Data Protection Regulation (GDPR) guidance.

\section{Research Design}

A descriptive research design was adopted throughout this study to address the exploratory research questions described above.

\section{Procedure}

Ethical approval was gained from the Coventry University ethics committee prior to data analysis commencing. Once ethical approval had been granted, the datasets were provided to the principle investigator in the form of two Microsoft Excel spreadsheets, covering the JanuaryDecember 2015 and January-December 2016 periods. These two datasets were combined into a single Excel spreadsheet, and the data were screened and cleaned for analysis to take place.

\section{Analysis}

The data were analysed utilising the pivot table, pivot charts and descriptive statistics functions within Microsoft Excel in order to depict the findings.

\section{Results}

In order to address the aforementioned research questions, each question was broken down into several smaller research questions, as discussed below.

\section{RQ1. "Who?": What is the socio-demographic and behavioural profile of subjects (i.e. hostage takers/individuals-in-crisis) involved in HCN deployments?}

\section{What is the gender breakdown of subjects involved in HCN deployments?}

The majority of incidents involved male subjects $(n=120$; $72.3 \%)$, with $24.1 \%(n=40)$ of incidents involving female subjects and subject gender being unrecorded in 3.6\% $(n=$ 6) of the incidents.

What is the age range of subjects and typical age of male/female subjects involved in HCN deployments?

Subjects were aged between $10-14$ and $60+$ years old. ${ }^{4}$ Subject age was not recorded $5.4 \%$ of cases $(n=9)$. The most frequently occurring (i.e. modal) age category for male subjects was the age 20-29 category, with 42 incidents (i.e. $36.8 \%$ ) involving males in this category. The most frequently occurring (modal) age category for both male and female subjects was the 20-29 years category (36.8\% of male subjects; $35.0 \%$ of female subjects). The next most frequently occurring age category for female subjects was the 10-19 category (30.0\%), suggesting that female subjects tend to present in younger age categories than male subjects (i.e. $65.0 \%$ of female subjects presented between the ages of 10 and 29 as opposed to $43.8 \%$ of male subjects presenting in this age range). Please refer to Table 1 for further information relating to subject age and gender.

\section{What are the subject impact factors/precipitating factors for the incidents?}

A breakdown of the subject impact factors recorded is detailed in Table 2, with the most frequently occurring impact factor being identified as "threat of suicide" or suicidal ideation in the subject $(n=85 ; 51.2 \%)$. The next most frequently identified impact factors were "presence of psychological disorder" $(n=74 ; 44.6 \%)$ and "relationship difficulties" $(n=48 ; 28.9 \%)$.

What proportion of incidents are expressive ${ }^{5} /$ instrumental $^{6}$ in nature?

The majority of incidents were categorised as being "expressive" $(n=125 ; 78.1 \%)$ as opposed to "instrumental" $(n=24$; $15.0 \%$ ), suggesting that the majority of incidents are motivated primarily by emotional needs, as opposed to rational and instrumental needs. No female subjects were categorised as being instrumental, whereas $20.0 \%(n=24)$ of male subjects were categorised as being instrumental in relation to their behaviour.

\footnotetext{
${ }^{4}$ Unable to specify exact lowest/highest age or mean age of subjects as data was recorded in age categories as opposed to exact age of subject.

${ }^{5}$ Expressive incidents are those wherein the motivation is intangible (i.e. the subject does not need the authorities and there is no attempt to utilise the hostage taker/victim as some sort of leverage or to obtain a demand). Expressive incidents tend to involve subjects who are highly emotionally aroused, and there is no clear goal to the incident (Vecchi et al. 2005).

${ }^{6}$ Instrumental incidents are those wherein the motivation is tangible and goaldirected. These incidents tend to involve the use of hostages in order to obtain some sort of substantive demand (Vecchi et al. 2005).
} 
Table 1 Frequency data depicting age and gender of subjects

\begin{tabular}{lcll}
\hline Age categories & Male subjects $(n=114), n(\%)$ & Female subjects $(n=40), n(\%)$ & Total $(N=154), n(\%)$ \\
\hline $10-19$ & $8(7.0 \%)$ & $12(30.0 \%)$ & $20(13.0 \%)$ \\
$20-29$ & $42(36.8 \%)$ & $14(35.0 \%)$ & $56(36.4 \%)$ \\
$30-40$ & $36(31.6 \%)$ & $7(17.5 \%)$ & $43(27.9 \%)$ \\
$40-50$ & $20(17.5 \%)$ & $4(10.0 \%)$ & $24(15.6 \%)$ \\
$60+$ & $8(7.0 \%)$ & $3(7.5 \%)$ & $11(7.1 \%)$ \\
\hline
\end{tabular}

Age categories have been modified for the final version of the NNDD to reflect the following age categories: 10 $14,15-19,20-24,25-29,30-34,35-39,40-44,45-49,50-54,55-59,60+$

RQ2. "What and where?": What is the contextual profile of hostage and crisis incidents? I.e. what are the key situational/behavioural characteristics of HCN deployments?

\section{How many deployments are encountered by HCNs in Norfolk/Suffolk?}

There was a total of 166 deployments recorded across the two forces between January 2015 and December $2016(n=63$ in $2015 ; n=103$ in 2016), with $132(79.5 \%)$ of these deployments relating to Norfolk Constabulary and 34 (20.5\%) relating to Suffolk Constabulary. ${ }^{7}$

\section{What is the most frequently occurring time of day} for deployments?

The majority of incidents occurred between the hours of 12 noon and $6 \mathrm{pm}(n=58 ; 35.0 \%)$, with the next most frequently occurring time category being $6.01 \mathrm{pm}-12$ midnight $(n=52$; $31.2 \%$ ). The least frequently occurring time category was between 12.01 and 6.00 am $(n=20 ; 12.0 \%)$ (please refer to Table 3).

\section{What is the most frequent month of deployment?}

The most frequent months of deployment were July $(n=23$; $13.9 \%)$ and December $(n=20 ; 12.0 \%)$, and the least frequent months of deployment were May $(n=8 ; 4.8 \%)$, March $(n=$ $10 ; 6.0 \%)$ and September $(n=10 ; 6.0 \%)$ (please refer to Table 4).

\section{What is the most frequent day of the week for deployments?}

Incidents occurred across all days of the week, with the most incidents occurring on a Wednesday $(n=30 ; 18.1 \%)$ and the least incidents occurring on a Tuesday $(n=20 ; 12.0 \%)$. Incidents occurring at the weekend $(n=47)$ constituted $28.3 \%$ of deployments (please refer to Fig. 1).

\footnotetext{
${ }_{7}^{7}$ Note shorter data collection period for Suffolk Constabulary (i.e. March 2015-December 2016).
}

\section{How long do incidents take to resolve?}

The total number of $\mathrm{HCN}$ hours required before resolution was recorded for 157 cases (data were missing for 9 cases). The total number of HCN deployment hours over the 24month period was $646.5 \mathrm{~h}$. Incidents ranged in length from 0 to $80 \mathrm{~h}$, with a mean resolution time of $4.1 \mathrm{~h}$. The modal length of time for incident resolution was $1 \mathrm{~h}$, suggesting that the majority of cases were resolved within a 1-h time frame.

\section{Where do most incidents occur (i.e. location of strongholds/crisis incidents)?}

Please refer to Table 5 for details of the stronghold locations reported. The majority $(n=91 ; 54.8 \%)$ of incidents took place

Table 2 Frequencies of subject impact factors

\begin{tabular}{|c|c|c|c|}
\hline Subject impact factor & $\begin{array}{l}\text { Number of } \\
\text { subjects }(n)\end{array}$ & $\begin{array}{l}\text { Percentage of } \\
\text { subjects }(\%)\end{array}$ & Rank \\
\hline Threat of suicide & 85 & 51.2 & 1 \\
\hline $\begin{array}{l}\text { Psychological } \\
\text { disorder }\end{array}$ & 74 & 44.6 & 2 \\
\hline $\begin{array}{l}\text { Relationship } \\
\text { difficulties }\end{array}$ & 48 & 28.9 & 3 \\
\hline Drug abuse & 41 & 24.7 & 4 \\
\hline $\begin{array}{l}\text { Subject deliberate } \\
\text { self-harm }\end{array}$ & 36 & 21.7 & 5 \\
\hline $\begin{array}{l}\text { Previous suicide } \\
\text { attempt }\end{array}$ & 35 & 21.1 & 6 \\
\hline Alcoholism & 26 & 15.7 & 7 \\
\hline Domestic abuse & 24 & 14.5 & 8 \\
\hline Separation or divorce & 19 & 11.4 & 9 \\
\hline Social isolation & 18 & 10.8 & 10 \\
\hline Housing & 8 & 4.8 & 11 \\
\hline Physical health & 8 & 4.8 & 11 \\
\hline Other & 8 & 4.8 & 11 \\
\hline Sexual abuse & 7 & 4.2 & 12 \\
\hline Unemployment & 7 & 4.2 & 12 \\
\hline Other substance abuse & 6 & 3.6 & 13 \\
\hline Economic difficulties & 6 & 3.6 & 13 \\
\hline $\begin{array}{l}\text { Work or study } \\
\text { difficulties }\end{array}$ & 5 & 3.0 & 14 \\
\hline Bereavement & 3 & 1.8 & 15 \\
\hline
\end{tabular}


Table 3 Frequencies of incident start times

\begin{tabular}{llll}
\hline $\begin{array}{l}\text { Incident start } \\
\text { time }\end{array}$ & $\begin{array}{l}\text { Number of incidents } \\
(n)\end{array}$ & $\begin{array}{l}\text { Proportion of incidents } \\
(\%)\end{array}$ & Rank \\
\hline $12.00-6.00 \mathrm{pm}$ & 58 & 35.0 & 1 \\
$6.01-12.00 \mathrm{pm}$ & 52 & 31.3 & 2 \\
$6.01-11.59$ am & 35 & 21.1 & 3 \\
$12.01-6.00$ am & 20 & 12.0 & 4 \\
Not stated & 1 & 0.6 & 5 \\
\hline
\end{tabular}

in a dwelling/domestic premises (i.e. house/flat), with the next most frequently occurring categories of incident location consisting of bridges $(n=17 ; 10.2 \%)$, parks/woodland ( $n=$ $9 ; 5.4 \%)$ and on the street/road $(n=9 ; 5.4 \%)$.

\section{Where do most incidents occur geographically in relation to force areas?}

Full and accurate postcodes of incidents were recorded for 135 incidents, ${ }^{8}$ and these data were analysed using the Mapping Sheets by the XS application available as an add-on in Google spreadsheets to provide a map of incident "hot spots". Please refer to Fig. 2 for details of incident locations across both geographical regions. In relation to the Norfolk region, the main hot spot areas tended to be located in Norwich and Great Yarmouth, with the majority of incidents being clustered within the Norwich city centre area (please refer to Fig. 3). In relation to the Suffolk region, the main hot spot areas tended to be in Ipswich city centre area. Most locations (i.e. 94.1\%) were deployed to on a single occasion; however, 8 specific postcodes (i.e. $5.9 \%$ ) were deployed to on more than one occasion (postcodes redacted).

\section{What types/categories of incident are typically/most frequently encountered by HCNs?}

The types of incident encountered by HCNs are depicted in Table 6 . The most frequently occurring (modal) category of incident involved subjects who were suicidal/threatening to self-harm, with 73 (i.e. $44.0 \%$ ) of the incidents falling into this category. The next most frequently occurring categories of incident involved HCNs being deployed in a firearms/ operational support capacity $(n=24 ; 14.5 \%)$ and HCNs being deployed to respond to high-risk/vulnerable missing persons (MISPERs) $(n=22 ; 13.3 \%)$

\footnotetext{
${ }^{8}$ A total of 28 incidents did not include full postcodes and 2 incidents were located outside of the UK.
}

Table 4 Frequencies of month of incident occurrence

\begin{tabular}{lllc}
\hline $\begin{array}{l}\text { Month of } \\
\text { incident }\end{array}$ & $\begin{array}{l}\text { Number of incidents } \\
(n)\end{array}$ & $\begin{array}{l}\text { Proportion of incidents } \\
(\%)\end{array}$ & Rank \\
\hline July & 23 & 13.9 & 1 \\
December & 20 & 12.0 & 2 \\
November & 18 & 10.8 & 3 \\
January & 17 & 10.2 & 4 \\
April & 13 & 7.8 & 5 \\
June & 13 & 7.8 & 5 \\
October & 12 & 7.2 & 6 \\
February & 11 & 6.6 & 7 \\
August & 11 & 6.6 & 7 \\
March & 10 & 6.0 & 8 \\
September & 10 & 6.0 & 8 \\
May & 8 & 4.8 & 10 \\
Not Stated & 1 & 0.6 & \\
\hline
\end{tabular}

\section{What proportion of incidents involves subjects who are intoxicated?}

A total of $15.7 \%(n=26)$ of subjects were recorded as having alcoholism as a subject impact factor, $24.7 \%(n=41)$ of subjects were recorded as having drug abuse as a subject impact factor and $3.6 \%(n=3)$ of subjects were recorded as having other substance abuse as a subject impact factor. Cumulatively, therefore, $44.0 \%(n=73)$ of subjects had a suspected or actual history of substance and/or alcohol abuse ${ }^{9}$, suggesting that this is a relevant factor within subject crisis precipitation.

\section{What proportion of incidents involves subjects with mental} health problems/mental health precipitated crises?

A total of 14 incidents (i.e. 8.4\%) were categorised as mental health precipitated sieges (with or without victims) and $44.6 \%$ $(n=74)$ of subjects were recorded as having a psychological disorder as a subject impact factor.

\section{What proportion of incidents involves subjects who are suicidal/threatening to harm themselves?}

A total of 73 incidents (i.e. $44.0 \%$ ) were categorised as involving suicidal individuals or subjects threatening to harm themselves. A total of $21.1 \%(n=35)$ of subjects were recorded as having made a previous suicide attempt and $51.2 \%(n=85)$ of

\footnotetext{
${ }^{9}$ Note that it is not possible to determine whether subjects were specifically under the influence of drugs and/or alcohol at the time of the crisis incident from the current dataset. It would be helpful if the national database provides an option for HNCs to record whether subjects are believed to be intoxicated/ under the influence of substances at the time of the incident.
} 
Fig. 1 Number of incidents occurring on each day of the week

\section{Incident Count by Day of the Week}

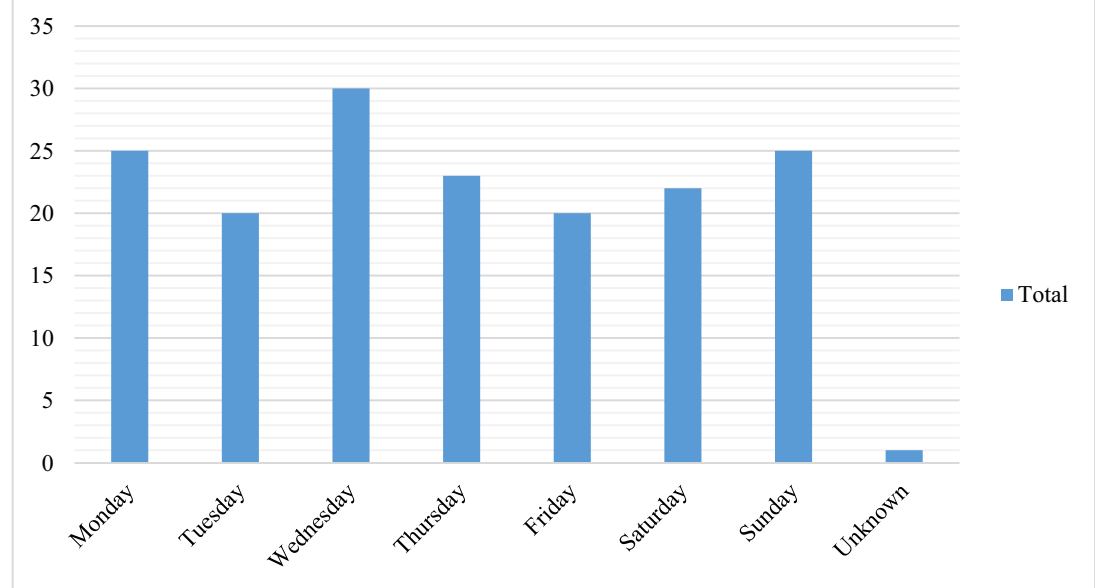

subjects were recorded as having threatened to commit suicide.

\section{What proportion of incidents involve overt/covert negotiation and what proportion of incidents are classified as "red centres" (i.e. involve kidnap and extortion)?}

The majority of deployments involved overt negotiation ( $n=$ $155 ; 93.4 \%$ ) with only 8 incidents (i.e. $4.8 \%$ ) involving covert negotiation in the form of kidnap and extortion/pseudo-kidnapping ${ }^{10}$ situations.

\section{What proportion of incidents involves the presence of hostages/victims ${ }^{11}$ ?}

A total of $6.6 \%$ of incidents $(n=11)$ were recorded as having involved either hostages $(n=8 ; 4.8 \%)$ or victims $(n=3$; $1.8 \%)$. All of the incidents $(n=11 ; 100 \%)$ involving hostages or victims were perpetrated by male subjects.

\section{What proportion of incidents involves weapons?}

A total of $53.6 \%$ of incidents $(n=89)$ involved some form of weapon, with the most frequently utilised weapons being bladed articles $(29.5 \%$ of incidents) and firearms $(13.3 \%$ of incidents) (please refer to Table 7). Weapons were not overtly referenced or apparent within $35.5 \%$ of incidents $(n=59)$, and

\footnotetext{
${ }^{10}$ According to Grubb et al. (2019), pseudo-kidnapping constitutes "crime in action" situations that are referred to colloquially as "bad-on-bad" kidnappings. These types of kidnappings tend to involve gang or criminal vendettas, organised crime or drug dealer conflict or disputes, with one "bad" party taking one of the other bad party's family members hostage in order to settle an outstanding debt of some kind.

${ }^{11}$ A victim is an individual who has been prevented from leaving a premises by the subject (i.e. there is no direct threat to the victims but they are being prevented from leaving the premises or are too frightened to leave because the person in control does not want them to leave) (Grubb et al. 2019).
}

data relating to weapons was missing for 18 deployments (i.e. $10.8 \%)$.

\section{What proportion of incidents could be classified as "suicide-by-cop" cases?}

A total of 6 incidents $(3.6 \%)$ were recorded as involving suicide-by-cop scenarios (data were missing in relation to this variable for 5 incidents $(3.0 \%)$ ). All $6(100 \%)$ of the suicideby-cop incidents involved male subjects.

\section{RQ3. "How?": How are hostage/crisis incidents resolved by HCNs?}

\section{What proportion of incidents was successfully resolved?}

Please refer to Table 8 for details of incident outcomes. A total of 149 incidents $(89.8 \%)$ were resolved without injury to the subject. ${ }^{12}$ One case $(0.6 \%)$ was reported to involve injury to the subject. Subject suicide was recorded in a single case $(0.6 \%)$ involving a high-risk missing person.

How were incidents resolved (i.e. what police method/tactic was utilised to resolve hostage/crisis incidents)?

The majority of incidents ( $n=85 ; 51.2 \%)$ were resolved using negotiation, $27.7 \%(n=46)$ of incidents were resolved via a non-negotiated surrender, $7.2 \%(n=12)$ of incidents required

\footnotetext{
${ }^{12}$ Please note that data was missing in relation to incident outcome for 15 cases which means that it is difficult to provide an accurate/exact figure for the number of successfully resolved incidents.

${ }^{0}$ The method of communication utilised is rated by the HCN on a scale of 1 to 5 , with 1 being the least effective and 5 being the most effective. $M$ represents the mean effectiveness score for each method of communication.
} 
Table 5 Frequencies of incident/stronghold locations

\begin{tabular}{llll}
\hline Incident location & $\begin{array}{l}\text { Number of } \\
\text { incidents }(n)\end{array}$ & $\begin{array}{l}\text { Proportion of } \\
\text { incidents (\%) }\end{array}$ & Rank \\
\hline House/flat & 91 & 54.8 & 1 \\
Bridge & 17 & 10.2 & 2 \\
Park/woodland & 9 & 5.4 & 3 \\
Street/road & 9 & 5.4 & 3 \\
Car park & 6 & 3.6 & 4 \\
Vehicle (car/van/lorry) & 6 & 3.6 & 4 \\
Commercial premises & 5 & 3.0 & 5 \\
$\quad$ (closed to public) & & 3.0 & 5 \\
Missing/blank & 5 & 2.4 & 6 \\
Hospital & 4 & 1.8 & 7 \\
School & 3 & 1.2 & 8 \\
Beach & 2 & 1.2 & 8 \\
Commercial premises & 2 & & \\
$\quad$ (open to public) & & 1.2 & 8 \\
Unknown location & 2 & 0.6 & 9 \\
Barn/outbuilding & 1 & 0.6 & 9 \\
Cliff edge & 1 & 0.6 & 9 \\
Hostel for vulnerable & 1 & 0.6 & 9.6 \\
$\quad$ adults & 1 & & 9 \\
Vehicle (boat) & 1 & & 9 \\
Other & & &
\end{tabular}

firearms tactical intervention and 3.6\% $(n=6)$ of incidents required PSU tactical intervention to resolve.

\section{Which method of communication was most commonly utilised/perceived to be most effective by HCNs?}

Face-to-face communication was the most commonly utilised method of communication $(n=58 ; 34.9 \%)$. Additional methods of communication were utilised in the following proportions: Telephone communication via negotiator cell at police headquarters or at incident $(n=45 ; 27.1 \%)$, not stated ( $n=45 ; 27.1 \%)$, text messaging $(n=13 ; 7.8 \%)$, social media online chat $(n=3 ; 1.8 \%)$ and no communication $(n=2$; $1.2 \%)$. Telephone communication was perceived as being the most effective method of communication by HCNs $(M=$ $4.67^{13}$ ), with face-to-face communication being perceived as the second most effective method $(M=4.47)$. Text messaging was perceived as the least effective method of communication $(M=2.77)$.

\footnotetext{
${ }^{13}$ The method of communication utilised is rated by the HCN on a scale of 1 to 5 , with 1 being the least effective and 5 being the most effective. $M$ represents the mean effectiveness score for each method of communication.
}

\section{How often were third-party intermediaries (TPIs) used and how helpful were they?}

TPIs were utilised in 18 cases $(10.8 \%)$ and included the use of family members $(n=11)$, a friend $(n=3)$, other ${ }^{14}(n=3)$ and a public official $(n=1)$. The public official received the highest mean helpfulness score ${ }^{15}(M=5.0)$, then the use of friends $(M=3.3)$, then the use of other TPIs $(M=3.0)$ and then the use of family members $(M=2.45)$. As such, whilst family members were most frequently utilised as TPIs, they were perceived as being the least effective/helpful by HCNs.

\section{How often were advisors/mental health professionals used and how helpful were they?}

Advisors were utilised on four occasions (2.4\%) and included the use of a cultural advisor, a medical practitioner, other (a mental health nurse) and a psychiatrist/psychologist (each on a single occasion). The cultural advisor and medical practitioner were rated as being the most helpful (each with a rating of 5), with the psychiatrist/psychologist and mental health nurse receiving ratings of 4 and 2 , respectively.

\section{Discussion}

The current findings provide the first empirical insight into $\mathrm{HCN}$ deployments in the UK. Access to data provided by $\mathrm{HCNs}$ in relation to the deployments they have completed over a 24-month period has enabled a picture of the nature and extent of HCN deployment in two English police forces to be developed. The findings help to shed light on the discipline of HCNn and tell us more about the day-to-day role of HCNs in English police forces, something which has previously only been understood from an anecdotal or operational perspective. Whilst exploratory in nature and based on a fairly small pilot dataset from two forces, the findings provide a platform for further academic analysis and research which can be used to introduce the concept of evidence-based HCNn and enhance evidence-based policing more generally (something which is heavily promoted by the College of Policing (2014) Five-Year Strategy). This project has also acted as a validity check for the database in its current format and has allowed for several "glitches" to be identified at the testing phase to enhance the overall quality of the national database when it was rolled out nationally.

When considering the socio-demographic profile of subjects, the findings suggest that men are by far the most

\footnotetext{
14 This included the following: a boyfriend, an ex-partner and a mental health nurse.

${ }^{15}$ When utilised, TPIs and advisors are rated by the HCN on a scale of 1 to 5 , with 1 being the least helpful and 5 being the most helpful.
} 
Fig. 2 Locations of $\mathrm{HCN}$ deployment incidents across the Norfolk and Suffolk regions

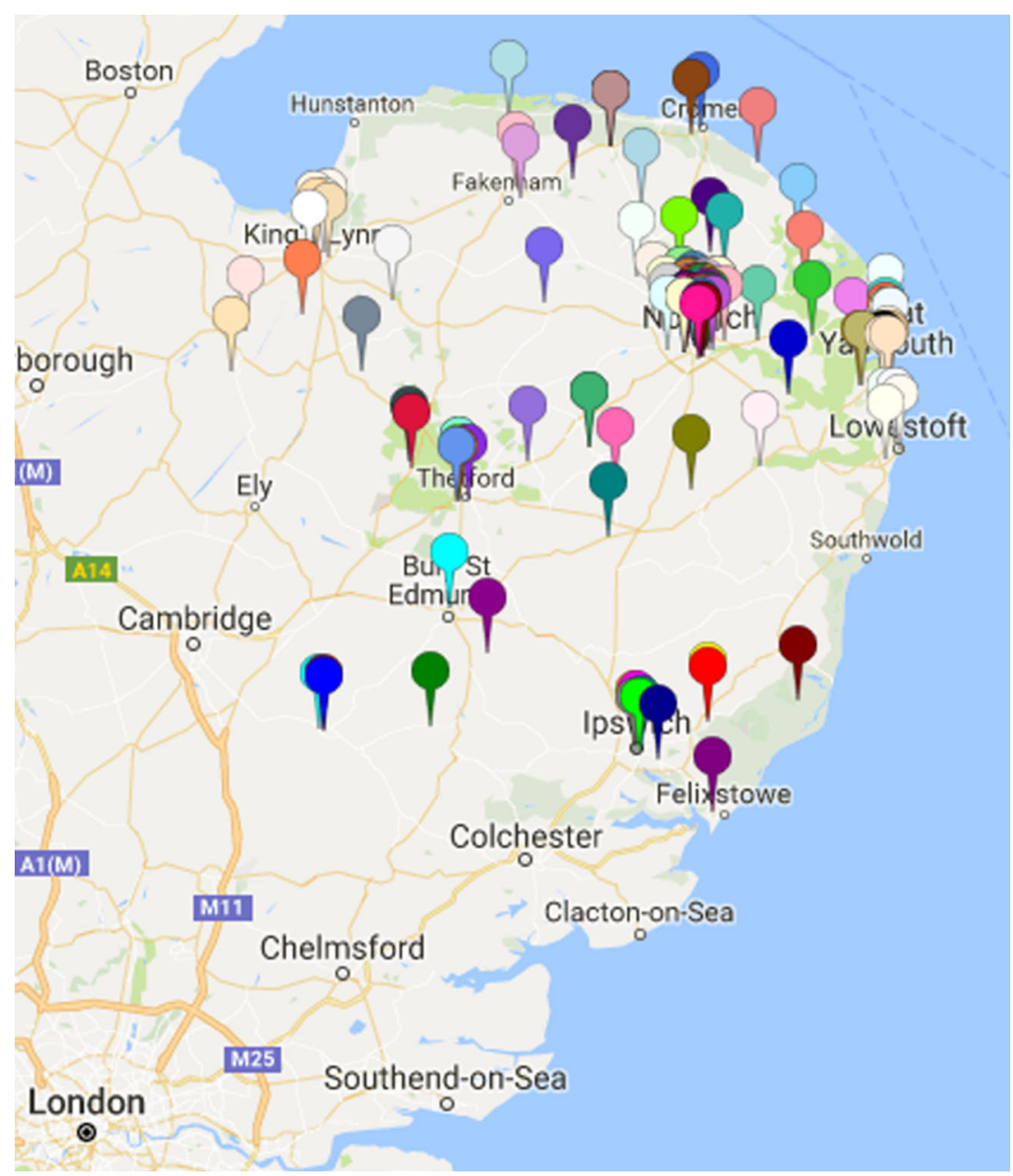

commonly encountered subjects (i.e. $72.3 \%$ ), a finding that supports the Scottish work by Alexander (2011) who reported $83.0 \%$ of perpetrators within his sample as being male. The most commonly presenting age category was 20-29, with $36.4 \%$ of subjects falling into this age bracket. Both male and female subjects were most likely to present in this age bracket (with $36.8 \%$ of male subjects and $35.0 \%$ of female subjects falling into this age category, respectively). Whilst collectively the 30-40 age category was the next most frequently occurring category, the next most frequently occurring age category for females was the 15-19 category (i.e. $30.0 \%$ of female subjects were recorded as being between the ages of 15 and 19 years old), suggesting that HCNs may be more likely to encounter younger subjects (i.e. under the age of 20) when they are female. Although not differentiated in terms of gender, similar findings are reported by Alexander (2011), who found that perpetrators (i.e. subjects) tended to fall into the 21-26 or 33-38 age categories, and Lipetsker (2004), who cites American data from the HOBAS, NYPD and Feldmann databases, which demonstrates that young adults (i.e. 2029 years) were involved in $29.8 \%, 50.5 \%$ and $35.3 \%$ of incidents, respectively. The current data, tangentially at least, suggests that HCNs are most likely to encounter subjects between the ages of 20 and 40 years old.

Whilst a variety of different factors were recorded as playing a role in the crisis incident, overwhelmingly, the subject profile depicted individuals who were experiencing personal, emotional or psychological crisis, with the top five subject impact factors constituting: threat of suicide $(51.2 \%)$, presence of psychological disorder $(44.6 \%)$, relationship difficulties $(28.9 \%)$, drug abuse $(24.7 \%)$ and deliberate self-harm $(21.7 \%)$. The vast majority of cases were expressive in nature (78.1\%) and being driven by emotional as opposed to instrumental or goal-directed needs. It is clear that subject mental health and psychopathology are key factors within many cases, with over half of the incidents $(51.2 \%)$ citing threat of suicide and $44.6 \%$ of incidents citing psychological disorder as relevant precipitating factors for the incident. These findings are further corroborated by the fact that $44.0 \%$ of cases were categorised as suicide/self-harm intervention, a far greater proportion than any other category listed. These findings are somewhat lower, but still in line with both the American and Scottish data, whereby Mohandie and Meloy (2010) found that $77.0 \%$ of cases recorded in the HOBAS database 


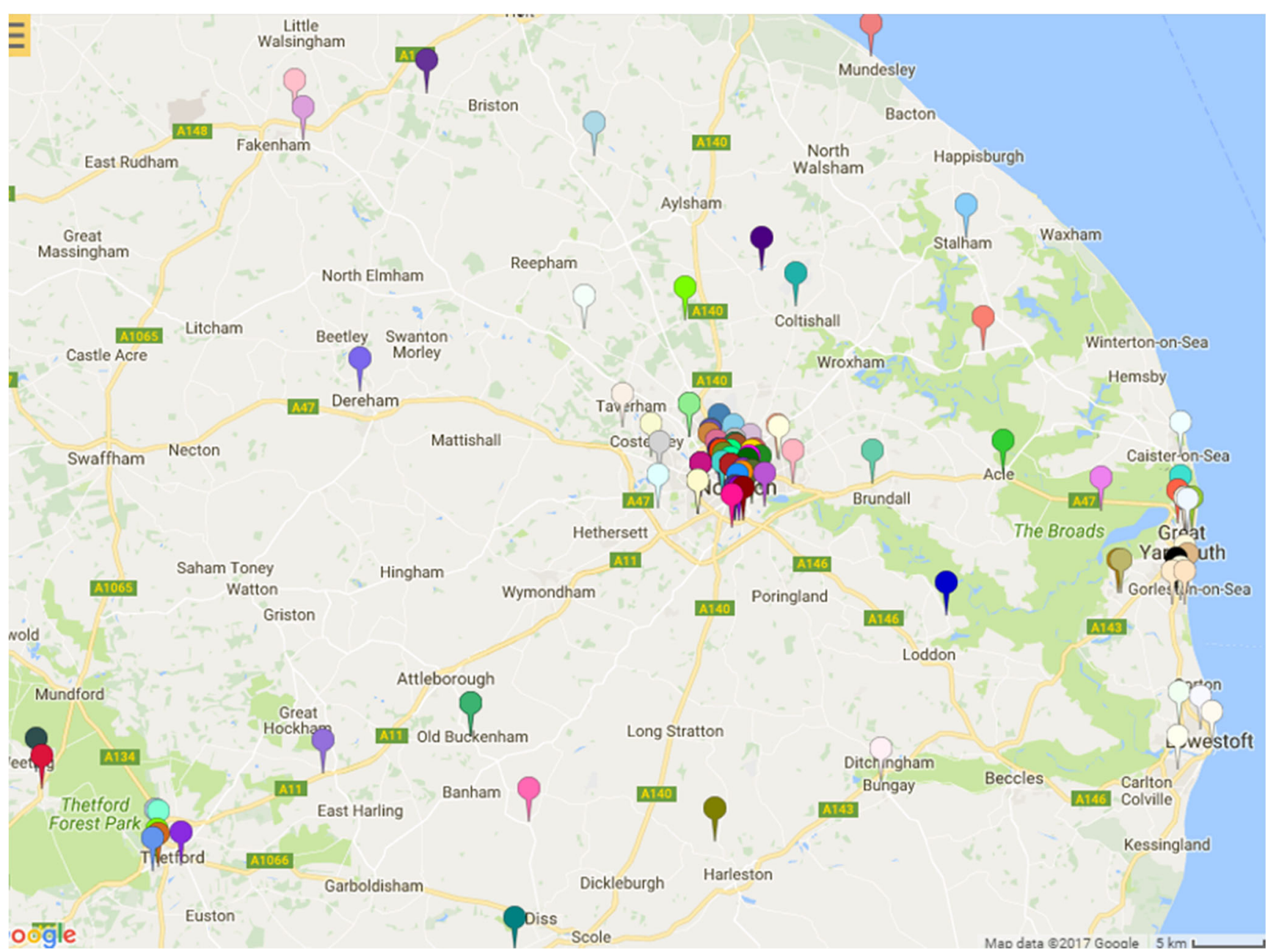

Fig. 3 Locations of HCN deployment by Norfolk Constabulary

between 1998 and 2006 involved suicidal individuals, and Alexander (2011) found that $59.0 \%$ of incidents involved a threat to the perpetrator's life through the risk of deliberate self-harm. At the other end of the spectrum, the emphasis on crisis as opposed to hostage negotiation is further exemplified by the limited number of incidents involving hostages or victims (i.e. 6.6\%), or being categorised as kidnap and extortion (4.2\%) or pseudo-kidnap and extortion cases $(0.6 \%)$, findings that are echoed by Alexander (2011) who reported hostages being involved in only $6.0 \%$ of the Scottish cases analysed. By far, the majority of cases, therefore, involved overt, as opposed to covert negotiation.

In relation to building a picture of the nature of $\mathrm{HCNn}$ in the Norfolk and Suffolk regions, the database included details relating to 166 incidents over a 24 -month period. If we take the data relating to 2016 alone (as this includes data recorded by both forces for a full 1-year period), HCNs were deployed on 103 occasions within both forces. This suggests tangentially, at least, that $\mathrm{HCNs}$ are being called out approximately 8-9 times a month across the two forces. In practice, of course, HCNs experience peaks and troughs in terms of their call-outs and may perhaps not be deployed at all 1 week and 3 or 4 times the next time they are "on call". Regional comparison of data will be much more enlightening and indicative once a full dataset is available from the NNDD. This will enable comparisons to be made both within and between countries, including comparison across metropolitan and rural forces, identification of frequencies of category of incident type and presentation of subject impact factors to provide a more accurate and representative picture of $\mathrm{HCN}$ deployment on a national level within the UK.

When looking at temporal data, most incidents tended to happen between 12 noon and 12 midnight (66.0\%). The largest proportion of incidents were recorded as happening at the weekend $(28.3 \%)$, with Wednesday being the most frequent week-day for deployment (18.1\%) and Tuesday/Friday being the least frequent weekday for deployment (12.0\%). Comparable data from Scotland found that incidents were most likely to happen on Mondays and least likely to happen on Fridays although a combined figure for weekend deployments is not presented (Alexander 2011). July and December were the months in which most deployments were recorded (13.9\% and $12.0 \%$, respectively), and the least number of deployments were recorded in May (4.8\%). However, it is worth noting that 
Table 6 Frequencies of incident category type

\begin{tabular}{|c|c|c|c|}
\hline Incident category type & $\begin{array}{l}\text { Number of incidents }(n) \\
\text { (male/female/ } \\
\text { unrecorded) }\end{array}$ & $\begin{array}{l}\text { Proportion of } \\
\text { incidents }(\%)\end{array}$ & Rank \\
\hline Suicide/self-harm & $73(40 / 31 / 2)$ & 44.0 & 1 \\
\hline $\begin{array}{l}\text { Firearms/operational } \\
\text { support }\end{array}$ & $24(23 / 0 / 1)$ & 14.5 & 2 \\
\hline $\begin{array}{l}\text { High-risk/vulnerable } \\
\text { MISPER }\end{array}$ & $22(14 / 7 / 1)$ & 13.3 & 3 \\
\hline $\begin{array}{l}\text { Mental health } \\
\text { precipitated siege } \\
\text { (no victims) }\end{array}$ & $13(11 / 2 / 0)$ & 7.8 & 4 \\
\hline Criminal barricade & $9(9 / 0 / 0)$ & 5.4 & 5 \\
\hline Criminal siege & $8(8 / 0 / 0)$ & 4.8 & 6 \\
\hline Kidnap and extortion & $7(5 / 0 / 2)$ & 4.2 & 7 \\
\hline $\begin{array}{l}\text { Dwelling-based } \\
\text { barricade }\end{array}$ & $3(3 / 0 / 0)$ & 1.8 & 8 \\
\hline Not recorded & 3 & 1.8 & 8 \\
\hline $\begin{array}{l}\text { Domestic siege (with } \\
\text { victims) }\end{array}$ & $2(2 / 0 / 0)$ & 1.2 & 9 \\
\hline $\begin{array}{l}\text { Mental health } \\
\text { precipitated siege } \\
\text { (with victims) }\end{array}$ & $1(1 / 0 / 0)$ & 0.6 & 10 \\
\hline $\begin{array}{l}\text { Pseudo-kidnap and } \\
\text { extortion ("bad on } \\
\text { bad") }\end{array}$ & $1(1 / 0 / 0)$ & 0.6 & 10 \\
\hline $\begin{array}{l}\text { Total number of } \\
\text { incidents }\end{array}$ & 166 & 100 & \\
\hline
\end{tabular}

MISPER missing person

$33.0 \%$ of all deployments were recorded between the months of November and January, suggesting that the winter period is a particularly risky time period for incidents. This may also

Table 7 Frequencies of types of weapons utilised by subjects

\begin{tabular}{llll}
\hline Type of weapon & $\begin{array}{l}\text { Number of } \\
\text { incidents }(n)\end{array}$ & $\begin{array}{l}\text { Proportion of } \\
\text { incidents (\%) }\end{array}$ & Rank \\
\hline $\begin{array}{l}\text { Nothing overtly referenced } \\
\quad \text { or apparent }\end{array}$ & 59 & 35.5 & 1 \\
$\begin{array}{l}\text { Bladed article } \\
\text { Firearm }\end{array}$ & 49 & 29.5 & 2 \\
$\begin{array}{l}\text { Data not recorded } \\
\text { Offensive weapon }\end{array}$ & 18 & 13.3 & 3 \\
$\begin{array}{l}\text { Offensive weapon and } \\
\quad \text { bladed article }\end{array}$ & 3 & 10.8 & 4 \\
$\begin{array}{l}\text { Firearm and bladed article } \\
\text { Petrol }\end{array}$ & 2 & 3.6 & 5 \\
$\begin{array}{l}\text { Firearm and offensive } \\
\quad \text { weapon }\end{array}$ & 1 & 1.8 & 6 \\
$\begin{array}{l}\text { Chemicals } \\
\begin{array}{l}\text { Fire and acid } \\
\text { Reference to bladed article }\end{array}\end{array}$ & 1 & 1.2 & 7 \\
$\quad$ (none present) & 1 & 1.2 & 7 \\
$\quad$ Reference to being armed & 1 & 0.6 & 8 \\
$\quad$ no elaboration) & & 0.6 & 8 \\
\hline
\end{tabular}

Table 8 Frequencies of incident outcome

\begin{tabular}{llll}
\hline Incident outcome & $\begin{array}{l}\text { Number of } \\
\text { incidents }(n)\end{array}$ & $\begin{array}{l}\text { Proportion of } \\
\text { incidents }(\%)\end{array}$ & Rank \\
\hline Negotiated surrender & 85 & 51.2 & 1 \\
Non-negotiated surrender & 46 & 27.7 & 2 \\
$\quad$ Not stated & 15 & 9.0 & 3 \\
$\quad$ Firearms tactical & 12 & 7.2 & 4 \\
$\quad$ intervention & & 3.6 & 5 \\
$\begin{array}{l}\text { Public safety unit (PSU) } \\
\quad \text { tactical intervention }\end{array}$ & 6 & 0.6 & 6 \\
$\begin{array}{l}\text { Subject injured } \\
\text { Subject suicide }\end{array}$ & 1 & 0.6 & 6 \\
\hline
\end{tabular}

peripherally be linked to seasonal affective disorder (SAD) which is known as "winter depression" because symptoms tend to be more apparent and more severe during the winter months (NHS Choices n.d.). Alexander's (2011) findings depict a slightly different picture in relation to monthly distribution of deployments, whereby incidents were most likely to happen in June and least likely to happen in March. Reasons for this difference are currently unclear; however, the findings would suggest that peak seasonal distribution for HCN deployment may differ across countries.

In terms of where incidents occur, both from a situational and geographical perspective, the most common stronghold location was within domestic premises, with $54.8 \%$ of incidents occurring within a house or flat and city centre locations (i.e. Norwich, Great Yarmouth and Ipswich) within both regions were deployment hot spots. The findings relating to stronghold location are in line with those of Alexander (2011), who reported $62.0 \%$ of incidents to have taken place in residential locations. Bridges were the next most frequently occurring stronghold location, with 17 bridge-related incidents $(10.2 \%)$ being recorded. Whilst target hardening is not possible when considering domestic premises, it is something that might be able to be considered in relation to bridges within the Norfolk and Suffolk regions. Similarly, identification of multiple deployments to the same postcode area within the Norfolk region could be used to look more specifically at these areas to establish whether these are areas that require particular attention in relation to repeated deployments to the same subject or whether there are particular factors that are relevant to the locale that are playing a role in subject crisis.

The situational incident characteristics depict an emphasis on suicide/self-harm as the core incident category for deployment (with $44.0 \%$ of cases being recorded in this category). Firearms/operational support constituted the next most frequent category of deployment (14.5\%) and then interaction with high-risk/vulnerable MISPERs (13.3\%). Other categories of deployment (including those involving hostages or victims) were also reported, suggesting that $\mathrm{HCN}$ deployment can be varied and may involve several different situational 
variables; however, the findings also suggest that the core business for HCNs involves responding to individuals who are threatening to harm themselves (as opposed to others), an assertion that is equally corroborated by Alexander's (2011) and Mohandie and Meloy's (2010) findings. Other salient situational variables include the role of subject intoxication/substance abuse and mental health problems. Almost half of the incidents $(44.0 \%)$ in the current dataset were recorded to involve subjects that had a suspected or actual history of substance and/or alcohol abuse in comparison with the slightly higher incidence rate of $64.0 \%$ reported by Alexander (2011). Similarly, $44.6 \%$ of the incidents were recorded to involve subjects with some form of psychological disorder. These findings highlight the potential relevance of substance abuse and mental health problems within crisis precipitation and suggest that an understanding of the psychology behind substance abuse/mental disorder (and associated behaviours) is an important component within the $\mathrm{HCN}$ training curriculum.

With regard to weapons, over half of the incidents (53.6\%) were recorded to have involved some form of weapon, with bladed articles being used in $29.5 \%$ of incidents and firearms being used in $13.3 \%$ of incidents. These findings align sympathetically with Alexander's (2011) data, which suggests that firearms were utilised in $14.0 \%$ of cases and that non-firearm weapons were utilised in $43.0 \%$ of cases. The findings imply that approximately half of the cases that HCNs are deployed to will involve some sort of weapon but that in many cases, this weapon is likely to be utilised by the subject as a means of inflicting self-harm/injury, as opposed to harming others, although the latter is always a risk that needs to be considered by HCNs and integrated into the dynamic risk/threat assessment performed by HCNs during the negotiation.

Further incident characteristics reveal that $\mathrm{HCNs}$ were deployed for a total of $646.5 \mathrm{~h}$ over the 24-month period, that the mean incident duration was $4.12 \mathrm{~h}$ and that the majority of cases were resolved within a 1-h time frame suggesting that most cases do not involve long and protracted negotiation/ levels of $\mathrm{HCN}$ deployment. The findings, reassuringly, suggest that most incidents $(89.8 \%)$ were resolved without injury to the subject (this equates to $98.7 \%$ of cases where outcome was reported, as outcome was not reported in 15 cases). Subject suicide was reported in one case $(0.6 \%)$ which is far lower than the $6.4 \%$ reported by Lipetsker (2004) in relation to the HOBAS data. Approximately half of the cases (51.2\%) were resolved via negotiated surrender which aligns with the HOBAS data reported by Lipetsker (2004), whereby $58.5 \%$ of cases were resolved via negotiation/surrender. These rates reflect a good level of success, particularly in relation to the lack of injury/death to subjects and it is worth noting that the rate of successful negotiated outcomes will depend on a vast number of uncontrollable variables, as opposed to the effectiveness of the $\mathrm{HCN}(\mathrm{s})$ per se.
In relation to the methods of communication utilised, data is missing for approximately a third of cases; however, faceto-face communication was the most commonly utilised method (34.9\%), with telephone communication being the second most commonly utilised method (27.1\%), suggesting that other forms of communication (such as text messaging or social media chat) are utilised far less than the traditional methods of communication. Intriguingly, despite face-toface communication being the most commonly utilised method, telephone communication was rated as the most effective method when utilised which is interesting when considered in light of face-to-face communication being reported as the preferred method of communication within preexisting research (Grubb 2016; Grubb et al. (2020). These findings suggest that more research needs to be performed in order to understand whether HCN is more effective when performed in a face-to-face or telephone format. There is a suggestion that computer-mediated communication (CMC) (including text messaging and online methods of communication) may have a place within modern-day hostage and crisis negotiation, and previous research by Almond and Budden (2012) found that $46 \%$ of the HCNs in their sample had experience of using text messages within a crisis negotiation environment. Although text messaging was only utilised within $7.8 \%$ of cases in the current study, the author purports that this is an area that may gain momentum in the future and that in some cases, the use of CMC may be more appropriate than other forms of communication due to its anonymity and means of reducing social barriers (Weisband 1992) between the subject and HCN. This may be particularly relevant when negotiating with younger subjects who may choose to interact via text-based mediums/ $\mathrm{CMC}$ rather than voice-based communication mediums. Research by Almond and Budden (2012) revealed that despite the active utilisation of text message by almost half of the sample surveyed, the use of text messaging was not being taught as part of the national negotiator training course at the time and $98.0 \%$ of UK HCNs stated that their organisation did not have a policy relating to the use of text messaging within a crisis negotiation environment, thereby suggesting that both policy development and training in relation to the use of text messaging or CMC are areas for development if these have not already been addressed on a national level.

The use of TPIs was recorded in $10.8 \%$ of cases, suggesting that this particular tactic is utilised infrequently by HCNs. Family members were most often utilised as TPIs; however, they were perceived as being the least effective, in comparison to other types of TPI (i.e. friends, other and public officials). Advisors were utilised even more infrequently (2.4\%), and these findings are likely to reflect the pre-existing concern relating to the use of third parties within overt hostage and crisis negotiation scenarios, whereby there is a lack of control regarding what TPIs/advisors may say/do and the potential for 
escalation of the crisis through dialogue which is not appropriate/helpful. Historically, early wisdom held that TPIs should not be used within hostage and crisis situations; however, it is now appreciated that as long as the who, how, when and why in relation to the TPI is considered (Slatkin 2010), use of TPIs can be both appropriate and effective in certain circumstances (Strentz 2012).

These findings are, of course, limited to some extent by several factors. Firstly, the findings are descriptive in nature, as opposed to providing a statistically supported meaning to the data. The findings, for example, cannot tell us which incident category type, for example, is more likely to be successfully resolved (at a level greater than chance would predict), or whether men are statistically more likely to use weapons than women. Secondly, the study provides insight into the characteristics of HCN deployments within two forces within a particular region in England and, as such, cannot be generalised to all forces within England and Wales or to the entire of the UK. It is likely that geographic differences exist between different locales within England and beyond, and future research conducted with the national database will allow for crossforce/country comparison to establish if such differences in the $\mathrm{HCN}$ deployment profile exist depending on force location and geographic composition. As such, the findings need to be interpreted with care and in line with the aforementioned caveats.

\section{Recommendations}

Suicide/self-harm intervention is at the forefront of HCN dayto-day business and training/CPD should continue to focus on/be directed towards providing HCNs with knowledge relating to (1) understanding the psychology behind suicide and self-harm and (2) understanding current, evidence-based, effective, suicide intervention techniques.

Substance-abuse and mental disorder are salient subject impact factors that are consistently encountered by HCNs during deployments. $\mathrm{HCN}$ training and CPD should, therefore, include a focus on providing knowledge in relation to (1) substance abuse (i.e. alcohol and drugs) and how it is likely to affect subject behaviour, (2) how to respond to/negotiate with subjects that are intoxicated and (3) psychological disorders and how to respond to/negotiate with subjects who display behaviours in line with certain forms of psychological disorder.

Whilst logistically dependent on force cadre numbers and $\mathrm{HCN}$ availability, numbers of HCNs on call could be increased during the months showing a greater number of deployments (i.e. November-January and July) to allow greater coverage of incidents during these months.

Regional analysis of deployment postcodes suggests an increased incidence of deployments within city centre areas (such as Norwich, Great Yarmouth and Ipswich), although this could simply be a result of the increased populations in these areas compared to more rural areas. Nevertheless, consideration should be placed on HCNs being located geographically close enough to be able to cover the region (and access key hot spot areas in particular) within a 45-min response time.

Eight specific postcodes in Norfolk were identified as having been deployed to on more than one occasion. Further analysis would be beneficial to identify whether these multiple deployments relate to individual subjects that are being deployed to on more than one occasion or whether these locations represent areas where $\mathrm{HCN}$ deployment is needed more regularly, and if so, why.

Recording procedures need to be improved in relation to certain aspects of the database to ensure that a full and accurate picture is being established in relation to HCN deployments. The author recommends that the NNDD should be formatted in a way that structures all questions as mandatory and requiring completion (even if the chosen answer is "not applicable").

Further empirical research is needed to explore the data more thoroughly using inferential statistics to provide a statistically driven analysis of the data. Such research could be used to identify the variables that are most highly correlated with/predict success within different HCNn scenarios and to guide $\mathrm{HCN}$ training and operational activity more convincingly.

At this stage, it would be imprudent to suggest that $\mathrm{HCN}$ training courses be realigned to reflect all of the findings from the current study as it is unclear whether these findings will be replicated on a national level once a full corpus of data has been recorded within the NNDD. Analysis of national level data will allow for a more in-depth analysis of HCN deployment across England, Wales and Northern Ireland, which will in turn, allow for training to be realigned/redesigned in a way that reflects realistic operational challenges as demonstrated by data recorded "in theatre" by operational HCNs.

\section{Conclusion}

The current study represents the first empirical analysis of $\mathrm{HCN}$ deployment data within England and demonstrates the first academic attempt to depict English HCNn in an operational sense on the basis of data recorded by HCNs in situ. The findings provide insight into (1) the socio-demographic characteristics of subjects encountered by HCNs, (2) the situational and behavioural characteristics of crisis incidents requiring HCN deployment and (3) how crisis incidents are resolved by HCNs in the Norfolk and Suffolk regions. Whilst the current findings are exploratory and descriptive in nature, future more detailed analysis using inferential statistics will enable more concrete recommendations to be made in relation to 
identifying variables that correlate with/predict positive outcomes in hostage and crisis situations. The current study represents a large and positive step towards understanding $\mathrm{HCNn}$ from an academic perspective, and the findings will help to enhance the concept of evidence-based HCNn within UK policing whilst providing a platform for further research to build upon.

Acknowledgements The author would like to thank Chief Inspector Louis Provart for his involvement and contribution to the project.

Funding Information This project was commissioned and funded by Norfolk Constabulary in the form of consultancy funding awarded to Dr Amy Rose Grubb (Principle Investigator).

Compliance with ethical standards Ethical approval was gained from the Coventry University ethics committee prior to data analysis commencing.

Open Access This article is licensed under a Creative Commons Attribution 4.0 International License, which permits use, sharing, adaptation, distribution and reproduction in any medium or format, as long as you give appropriate credit to the original author(s) and the source, provide a link to the Creative Commons licence, and indicate if changes were made. The images or other third party material in this article are included in the article's Creative Commons licence, unless indicated otherwise in a credit line to the material. If material is not included in the article's Creative Commons licence and your intended use is not permitted by statutory regulation or exceeds the permitted use, you will need to obtain permission directly from the copyright holder. To view a copy of this licence, visit http://creativecommons.org/licenses/by/4.0/.

\section{References}

ACPO, \& NPIA (2011) The use of negotiators by incident commanders. NPIA, London Retrieved from http://www.acpo.police.uk/ documents/TAM/2011/201112TAMOUNbyIC.pdf

Alexander D (2011) Hostage and crisis incidents: an evidence-based analysis to inform police negotiator training provision. SIPR Research Summary No: 6, March 2011. Dundee: The Scottish Institute for Policing Research. Retrieved from http://www.sipr.ac. uk/downloads/Research_Summaries/Research_Summary_6.pdf

Almond L, Budden M (2012) The use of text messages within a crisis negotiation: help or hindrance? J Police Crisis Negotiations 12:127. https://doi.org/10.1080/15332586.2011.593343

Boltz F, Dudonis K, Schultz D (1992) The counter-terrorism handbook: tactics, procedures and techniques. CRC Press, Boca Raton

Bridges S (2015) Chapter 2: mental health problems. In: Craig R, Fuller E, Mindell J (eds) Health survey for England 2014: health, social care and lifestyles. The Health and Social Care Information Centre, Leeds, pp 1-16

College of Policing (2014) Five year strategy, available at: http://www. college.police.uk/About/Documents/Five-Year_Strategy.pdf

Data Protection Act, c. 29 § 1 (1998)

Department of Justice (2006) Request for records disposition authority: job number NI-065-06-8. Hostage Barricade Database System (HOBAS). Retrieved from https://www.archives.gov/records$\mathrm{mgmt} / \mathrm{rcs} /$ schedules/departments/department-of-justice/rg-0065/n1065-06-008 sf115.pdf
Grubb A (2016) An exploratory mixed-methodological analysis of police hostage and crisis negotiation the United Kingdom (unpublished doctoral dissertation). Coventry University, Coventry

Grubb AR, Brown SJ, Hall P, Bowen E (2019) From "sad people on bridges" to "kidnap and extortion": understanding the nature and situational characteristics of hostage and crisis negotiator deployments. J Negot Confl Manag Res 12(1):41-65. https://doi.org/10. $1111 /$ ncmr.12126

Grubb AR, Brown SJ, Hall P, \& Bowen E (2020) From deployment to debriefing: Introducing the D.I.A.M.O.N.D. model of hostage and crisis negotiation. Police Practice and Research: An International Journal. Advance Online Publication. https://doi.org/10.1080/ 15614263.2019.1677229

Lipetsker A (2004) Evaluating the hostage barricade database system (HOBAS). J Police Crisis Negotiations 4:3-27. https://doi.org/10. 1300/J173v04n02 02

McMains M, Mullins W (1996) Crisis negotiations: managing critical incidents and situations in law enforcement and corrections. Anderson, Cincinnati

McMains M, Mullins W (2014) Crisis negotiations: managing critical incidents and hostage situations in law enforcement and corrections, 5 th edn. Routledge, New York

McManus S, Meltzer H, Brugha T, Bebbington P, Jenkins R (2009) Adult psychiatric morbidity in England, 2007: results of a household survey. The NHS Information Centre for Health and Social Care, London

Mental Health Foundation (2013) Starting today: the future of mental health services. Retrieved from https://www.mentalhealth.org.uk/ sites/default/files/starting-today.pdf

Miller L (2005) Hostage negotiation: psychological principles and practices. Int J Emerg Ment Health 7:277-298 Retrieved from https:// www.psychceu.com/miller/Miller_Hostage_Neg.pdf

Mohandie K, Meloy JR (2010) Hostage and barricade incidents within an officer-involved shooting sample: suicide by cop, intervention efficacy, and descriptive characteristics. J Police Crisis Negotiations 10: 101-115. https://doi.org/10.1080/15332581003799737

NHS Choices (n.d.) Seasonal affective disorder. Retrieved from: http:// www.nhs.uk/conditions/Seasonal-affective-disorder/Pages/ Introduction.aspx

Slatkin A (2010) Communication in crisis and hostage negotiations (2nd ed.). Springfield, IL: Charles C Thomas

Strentz T (2012) Psychological aspects of crisis negotiation (2nd ed.). Boca Raton: CRC Press

University of Manchester (2015) The national confidential inquiry into suicide and homicide by people with mental illness annual report 2015: England, Northern Ireland, Scotland and Wales July 2015. The University of Manchester, Manchester

Vecchi G, Van Hasselt V, Romano S (2005) Crisis (hostage) negotiation: current strategies and issues in high-risk conflict resolution. Aggress Violent Behav 10:533-551. https://doi.org/10.1016/j.avb.2004.10. 001

Weisband S (1992) Group discussion and first advocacy effects in computer-mediated and face-to-face decision making groups. Organ Behav Hum Decis Process 53:352-380

West Mercia Police (2009) Hostage and crisis negotiator policy. Force policy number 175. West Mercia Police: Force Operations Department. Retrieved from http://www.westmercia.police.uk/ assets/_files/documents/nov_09/wmp_1257873302_Hostage_ and Crisis Negotiator Po.pdf

Publisher's Note Springer Nature remains neutral with regard to jurisdictional claims in published maps and institutional affiliations. 